\title{
Sustained $\mathrm{Ca}^{2+}$ Entry Elicits Transient Postsynaptic Currents at a Retinal Ribbon Synapse
}

\author{
Joshua H. Singer and Jeffrey S. Diamond \\ Synaptic Physiology Unit, National Institutes of Health-National Institute of Neurological Disorders and Stroke, Bethesda, Maryland 20892
}

\begin{abstract}
Night (scotopic) vision is mediated by a distinct retinal circuit in which the light responses of rod-driven neurons are faster than those of the rods themselves. To investigate the dynamics of synaptic transmission at the second synapse in the rod pathway, we made paired voltage-clamp recordings from rod bipolar cells (RBCs) and postsynaptic AII and A17 amacrine cells in rat retinal slices. Depolarization of RBCs from $-60 \mathrm{mV}$ elicited sustained $\mathrm{Ca}^{2+}$ currents and evoked AMPA receptor (AMPAR)-mediated EPSCs in synaptically coupled amacrine cells that exhibited large, rapidly rising initial peaks that decayed rapidly to smaller, steady-state levels. The transient component persisted in the absence of feedback inhibition to the RBC terminal and when postsynaptic AMPA receptor desensitization was blocked with cyclothiazide, indicating that it reflects a time-dependent decrease in the rate of exocytosis from the presynaptic terminal. The EPSC waveform was similar when RBCs were recorded in perforated-patch or whole-cell configurations, but asynchronous release from RBCs was enhanced when the intraterminal $\mathrm{Ca}^{2+}$ buffer capacity was reduced. When RBCs were depolarized from $-100 \mathrm{mV}$, inactivating, low voltage-activated (T-type channel-mediated) $\mathrm{Ca}^{2+}$ currents were evident. Although $\mathrm{Ca}^{2+}$ influx through T-type channels boosted vesicle release, as reflected by larger EPSCs, it did not make the EPSCs faster, indicating that activation of T-type channels is not necessary to generate a transient phase of exocytosis. We conclude that the time course of vesicle release from RBCs is inherently transient and, together with the fast kinetics of postsynaptic AMPARs, speeds transmission at this synapse.
\end{abstract}

Key words: ribbon synapse; rod bipolar cell; AII amacrine cell; retina; scotopic vision; AMPA receptor

\section{Introduction}

Night (scotopic) vision is mediated by a neural circuit that comprises rod photoreceptors and a specific subset of retinal interneurons (for review, see Bloomfield and Dacheux, 2001). Rods make synapses onto rod bipolar cells (RBCs), which undergo sustained depolarization in response to light (Euler and Masland, 2000). RBC terminals contain synaptic ribbons and make synapses onto two postsynaptic elements from separate neurons: AII and A17 amacrine cells (Famiglietti and Kolb, 1975; Dacheux and Raviola, 1986). AIIs exhibit light responses with both transient and sustained components (Nelson, 1982; Kolb and Nelson, 1983; Dacheux and Raviola, 1986; Bloomfield and Xin, 2000) and make sign-conserving gap junctions with $\mathrm{ON}$ cone bipolar cells (CBCs) (Famiglietti and Kolb, 1975) and inhibitory, glycinergic synapses onto OFF CBCs (Pourcho and Goebel, 1985). Thus, AIIs transfer rod signals to the cone pathway and divide them into $\mathrm{ON}$ and OFF components. Light responses in A17 amacrine cells are sustained (Kolb and Nelson, 1983; Nelson and Kolb, 1985; Raviola and Dacheux, 1987; Menger and Wassle, 2000), and the A17 makes a reciprocal, inhibitory synapse onto the RBC termi-

Received Aug. 6, 2003; revised Sept. 22, 2003; accepted Sept. 24, 2003.

This work was supported by the National Institute of Neurological Disorders and Stroke (NINDS) Intramural Research Program and an NINDS Career Development Award to J.H.S. We thank M. Higgs, M. Holmgren, R. Nelson, and K. Swartz for helpful discussions.

Correspondence should be addressed to Dr. Joshua H. Singer, National Institutes of Health-National Institute of Neurological Disorders and Stroke, 36 Convent Drive, MSC-4066, Building 36, Room 2C09, Bethesda, MD 20892 4066. E-mail: singerj@ninds.nih.gov.

Copyright $\odot 2003$ Society for Neuroscience ～0270-6474/03/2310923-11\$15.00/0 nal (Kolb and Nelson, 1983; Dacheux and Raviola, 1986; Raviola and Dacheux, 1987).

This neural circuit is unique to mammals and conserved in all species studied to date. The light responses of its component neurons have been characterized extensively (Bloomfield and Dacheux, 2001), yet the dynamic properties of some synapses within the rod circuit are not well understood. In particular, some modification of the rod signal-the transformation of a slow, sustained depolarization into one with a transient initial phase-must occur at the RBC-AII synapse to allow temporal information to be encoded.

To examine the time course of neurotransmission at this synapse, we made paired, voltage-clamp recordings from synaptically connected RBCs and AIIs or A17s in rat retinal slices. We found that postsynaptic AMPA receptors (AMPARs) with rapid channel kinetics mediate EPSCs exhibiting transient and sustained components. The contribution of the transient component to the EPSC varied with the rate of presynaptic $\mathrm{Ca}^{2+}$ influx, indicating that it reflects intrinsically transient exocytosis from RBC terminals. We conclude that although RBCs are neurons that signal via graded potentials, this synapse is well suited to transfer information quickly.

\section{Materials and Methods}

Experiments were performed at $\sim 22^{\circ} \mathrm{C}$ in light-adapted, $200 \mu \mathrm{m}$ slices prepared from midtemporal retinas of Sprague Dawley rats (postnatal days 15-25). Retinas were isolated in artificial CSF (ACSF) bubbled with 95\% $\mathrm{O}_{2} / 5 \% \mathrm{CO}_{2}$ and containing (in $\mathrm{mm}$ ): $119 \mathrm{NaCl}, 26 \mathrm{NaHCO}_{3}, 10$ glucose, $1.25 \mathrm{NaH}_{2} \mathrm{PO}_{4}, 2.5 \mathrm{KCl}, 2.5 \mathrm{CaCl}_{2}, 1.5 \mathrm{MgCl}_{2}, 4$ NaLactate, 2 
NaPyruvate, and 0.5 ascorbic acid. Isolated tissue was embedded in low melting point agarose (3\% in ACSF with HEPES substituted for $\mathrm{NaHCO}_{3}$ ), and slices were cut on a Vibratome (Vibratome Corporation, St. Louis, MO) and stored at $\sim 22^{\circ} \mathrm{C}$. Slices were superfused during recordings with ACSF bubbled with 95\% $\mathrm{O}_{2} / 5 \% \mathrm{CO}_{2}$.

Neurons were visualized by infrareddifferential interference contrast (IR-DIC) video microscopy. Whole-cell recordings from AIIs and A17s were made using pipettes $(\sim 5 \mathrm{M} \Omega)$ containing (in mM): $100 \mathrm{CsCH}_{3} \mathrm{SO}_{3}, 20$ TEA-Cl, 20 HEPES, 10 EGTA, 4 MgATP, 0.4 NaGTP, and 0.1 methoxyverapamil. Holding potentials were corrected for a $\sim 10 \mathrm{mV}$ junction potential. Perforated-patch and whole-cell recordings (7-15 $\mathrm{M} \Omega$ pipettes) were made from RBCs. Unless indicated otherwise, the internal solution contained (in mM): $100 \mathrm{CsCH}_{3} \mathrm{SO}_{3}, 20$ TEA-Cl, 20 HEPES, 10 glutamic acid, 4 MgATP, and 0.4 NaGTP. For perforated-patch recordings, $0.2 \mathrm{~mm}$ EGTA and $0.5 \mathrm{mg} / \mathrm{ml}$ Amphotericin B (water-soluble formulation) were included. For whole-cell recordings, 0.2 or 10 mM EGTA or $1.5 \mathrm{~mm}$ BAPTA was added, and in some of these experiments, $10 \mathrm{~mm} \mathrm{Na}$ Phosphocreatine was included in the pipette solution. To isolate $\mathrm{Ca}^{2+}$ currents, in some experiments $\mathrm{N}$-methyl-D-glucamine methanesulfonate $\left(\mathrm{NMDG}^{+}\right)$or trimethylammonium acetate $\left(\mathrm{TMA}^{+}\right.$) replaced $\mathrm{CsCH}_{3} \mathrm{SO}_{3}$, and $1 \mathrm{~mm} \mathrm{C8}$ TEA-Cl (gift from M. Holmgren, National Institutes of Health, Bethesda, MD) was added to the internal solution. In some cases, fluorescent tracers (Alexa hydrazine 488 or 594; Molecular Probes, Eugene, OR) were included in the pipettes.

Postsynaptic access resistance was $<20 \mathrm{M} \Omega$ and compensated $70-95 \%$. In a sample of RBCs that included all types of recordings, presynaptic access resistance was $61 \pm 22 \mathrm{M} \Omega$ (mean \pm $\mathrm{SD} ; n=63$ ) and was uncompensated. The high presynaptic access resistance was primarily a consequence of the small pipettes that we used. Small pipettes, however, greatly improved our ability to obtain tight seals and long-lasting recordings from RBCs, thereby increasing the yield of paired recordings.

Generally, recordings were made in ACSF containing picrotoxin (100 $\mu \mathrm{M})$, strychnine $(0.5 \mu \mathrm{M}$ ), and tetrodotoxin (TTX, $0.25 \mu \mathrm{M}$ ) to block $\mathrm{GABA}_{\mathrm{A}}$ receptor-, glycine receptor-, and voltage-gated $\mathrm{Na}^{+}$channelmediated currents, respectively. Where noted, [1,2,5,6-tetrahydropyridin-4yl]methylphosphinic acid (TPMPA) $(50 \mu \mathrm{M})$ was added to block $\mathrm{GABA}_{\mathrm{C}}$ receptors. Drugs were obtained from Sigma (St. Louis, MO) or Tocris (except for TTX; Alamone Labs, Jerusalem, Israel). Recordings were made using two Axopatch 200B amplifiers or a single MultiClamp 700A amplifier (Axon Instruments, Foster City, CA). Currents were elicited at 15-17 sec intervals, low-pass filtered at $2-5 \mathrm{kHz}$, and digitized at $10 \mathrm{kHz}$ by an Instrutech ITC- 18 analog-to-digital board controlled by software written for Igor Pro (WaveMetrics). Presynaptic currents were leak-subtracted (P/4 protocol). Data analysis was performed using Igor Pro and Excel (Microsoft). Paired, twotailed $t$ tests or ANOVA were used to compare data sets. In all cases, significance was accepted as $p<0.05$. Unless indicated otherwise, data are presented as mean $\pm \mathrm{SE}$, and illustrated traces are averages of 5-10 responses.

\section{Results}

\section{EPSCs comprise fast and slow components}

Presynaptic RBCs and postsynaptic AIIs in retinal slices were identified by their morphology and position within the inner nuclear layer (INL) (Fig. 1A). RBC somata were in the outer
$\mathrm{C} 1$

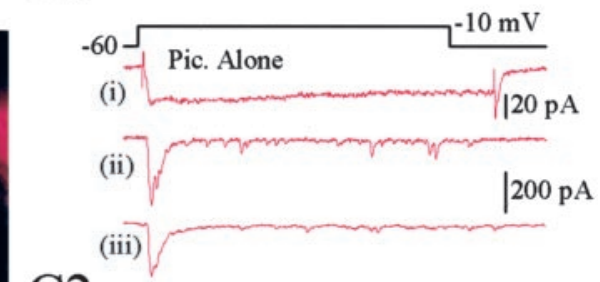

$\mathrm{C} 2$

(i)

(ii)

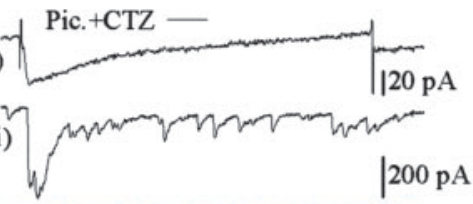

(iii)

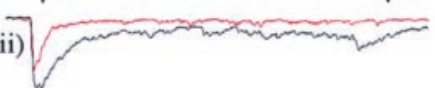

$\mathrm{C} 3$

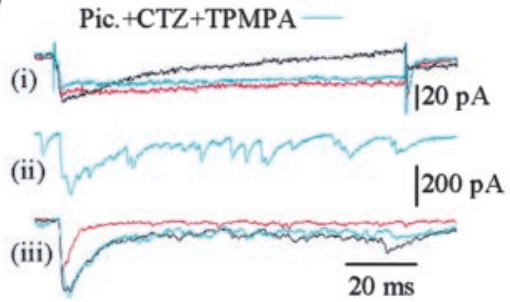

Figure 1. Synaptic transmission at the RBC-All synapse. A, Left, Retinal slice visualized by IR-DIC microscopy. Arrows indicate somata of an All amacrine cell (yellow) and an RBC (red). Right, Distinctive morphologies of an All (yellow) and an RBC (red) Averaged, leak-subtracted presynaptic current. ii, Single EPSC recorded in a postsynaptic All $\left(V_{\mathrm{m}}=-90 \mathrm{mV}\right)$. iii, Average of five EPSCS. C2, As in C1 but with CTZ (50 $\mu$; black trace) added. Gray traces are the same as in C1, duplicated for comparison. C3, As in (2 but with TPMPA (50 $\mu$ m; blue trace) added.

portion of the INL, immediately adjacent to the outer plexiform layer (OPL) (Fig. $1 \mathrm{~A}$, red arrow). In somatic voltage-clamp recordings, these neurons were characterized by high input resistances (in a subset of RBCs, $R_{\text {in }}=6.1 \pm 0.4 \mathrm{G} \Omega ; n=63$ ) and small, sustained $\mathrm{Ca}^{2+}$ currents after depolarizing voltage steps from $-60 \mathrm{mV}$ [cone bipolar cells exhibit larger, more transient $\mathrm{Ca}^{2+}$ currents (Pan, 2000)], and when filled with fluorescent tracers and viewed under epi-illumination, RBCs exhibited a single axon that extended through the INL and inner plexiform layer (IPL), terminating in a number of varicosities in the innermost portion of the IPL (Euler and Wassle, 1995; Hartveit, 1997) (Fig. $1 A$ ). AII amacrine cells were found at the border between the INL and IPL and had pear-shaped somata that protruded into the IPL and gave rise to one or two visible, primary dendrites (Veruki and Hartveit, 2002) (Fig. 1A, yellow arrow). These neurons were characterized by very high rates of spontaneous synaptic activity (Veruki et al., 2003) and a characteristic morphology that was visualized by epi-illumination of fluorescent tracers: a narrow, highly branched dendritic tree with large, distal varicosities (Fig. 1A).

For paired recordings, a whole-cell, voltage-clamp recording from an AII first was established; afterward, recordings were made from RBCs directly above the AII. Data acquisition com- 
menced $\sim 2$ min after the RBC recording was established. When two simultaneous recordings were established successfully, the likelihood that the RBC was connected synaptically to the AII was quite high. These recordings were stable, but the synaptic currents tended to run down with time, such that the practical lifetime of a single experiment was $\sim 15 \mathrm{~min}$. Synaptic currents were evoked at $15-17 \mathrm{sec}$ intervals, allowing $\sim 50$ responses to be collected during the average experiment.

The AII membrane potential was clamped at -60 or $-90 \mathrm{mV}$, and EPSCs were evoked by stepping the RBC $V_{\mathrm{m}}$ from -60 to -10 or $0 \mathrm{mV}$ for $100 \mathrm{msec}$ (Fig. $1 B$ ). This voltage step activated a $\mathrm{Ca}^{2+}$ current in the presynaptic RBC (Fig. $1 B$, ii) and evoked EPSCs that exhibited two distinct components (Fig. $1 B$, iii). The first was fast, rising in $\sim 1 \mathrm{msec}$ and decaying within $20 \mathrm{msec}$, giving rise to the EPSC peak. The second comprised small synaptic events that persisted throughout the duration of the presynaptic depolarization (Fig. 1C1). Presynaptic recordings were made first in perforated-patch and then in whole-cell configurations using $1.5 \mathrm{~mm}$ BAPTA as a $\mathrm{Ca}^{2+}$ chelator to approximate the endogenous buffer capacity of the bipolar cell terminal (Burrone et al., 2002). Because no differences between the two conditions were observed, the results from both were pooled, except where noted (a typical perforated-patch recording is shown in Fig. 6D).

When antagonists of inhibitory neurotransmitter receptors were excluded from the external solution (ACSF containing only TTX, to eliminate $\mathrm{Na}^{+}$spikes in AII amacrines coupled to the recorded AII) (Veruki et al., 2003), outward synaptic currents often were observed atop the presynaptic $\mathrm{Ca}^{2+}$ current (Protti and Llano, 1998; Pan et al., 2001) (Fig. 1B, i). Averaging and leak-subtracting a number of individual trials revealed a clear outward component of the presynaptic membrane current that rose in several milliseconds and decayed in $\sim 20 \mathrm{msec}$ (Fig. 1B, ii, and insets). Because the $E_{\mathrm{Cl}}{ }^{-}$of our internal solution was approximately $-50 \mathrm{mV}$, at $-10 \mathrm{mV}$ these outward currents were likely mediated by activation of GABA receptors (GABARs) by GABA released from A17 amacrine cells postsynaptic to the recorded RBC (Protti and Llano, 1998; Pan et al., 2001). Supporting this assertion, the outward synaptic currents were blocked by picrotoxin $(100 \mu \mathrm{M})$ (Fig. $1 B$,i, ii), a GABAR antagonist that, at this concentration, acts primarily at $\mathrm{GABA}_{\mathrm{A}} \mathrm{Rs}$ in the retina (Feigenspan et al., 1993; Pan and Lipton, 1995). In the presence of picrotoxin, addition of the $\mathrm{GABA}_{\mathrm{C}} \mathrm{R}$ antagonist, TPMPA (50 $\mu \mathrm{M}$ ), had no effect on the presynaptic membrane current (Fig. $1 B, \mathrm{i}, \mathrm{ii})$. Consequently, most of the following experiments were performed in the absence of TPMPA. Neither picrotoxin alone nor in combination with TPMPA altered the EPSC waveform, although we did observe small changes in the EPSC peak amplitude that we attribute to time-dependent rundown of the synaptic current amplitude (peak amplitudes $=291.5 \pm 60.2 \mathrm{pA}$, $261.0 \pm 53.6 \mathrm{pA}$, and $240 \pm 50.1 \mathrm{pA}$ for control, picrotoxin, and picrotoxin plus TPMPA, respectively; $n=6$ ). To assay changes in the EPSC waveform independent of rundown, we calculated $Q T_{1 / 2}$, the time at which one-half of the charge carried by the synaptic current had been transferred; this value was $21.7 \pm 4.1$ msec for control, $22.1 \pm 7.1 \mathrm{msec}$ for picrotoxin, and $20.7 \pm 6.6$ msec for TPMPA plus picrotoxin. The differences between these values are not significant ( $p=0.98$ by ANOVA; $n=6$ ). Consequently, it appears that the transient initial component of the EPSC persists in the absence of feedback inhibition onto RBC terminals.

Because the EPSC was transient when inhibitory synaptic transmission was blocked, its waveform likely arises from intrinsic properties of the synapse. To confirm that the transience did not arise solely from AMPAR desensitization, we compared EPSCs evoked in the absence or presence of $50 \mu \mathrm{M}$ cyclothiazide (CTZ), a compound that both blocks AMPAR desensitization and increases the affinity of the receptor for glutamate (Partin et al., 1993).

With picrotoxin present, CTZ increased the amplitude and slowed the decay of both the fast and slower components (Fig. 1C2) (percentage of control: peak current $=139 \pm 9 \%$; EPSC integral $=508 \pm 44 \% ; n=16$ ), but the EPSC retained its characteristic waveform, exhibiting a rapidly rising peak followed by a smaller, sustained component. Additionally, CTZ caused a pronounced change in the presynaptic membrane current (Fig. $1 C 2$ ); recordings showed a relatively large, slowly developing outward conductance elicited by voltage steps in the presence of CTZ. This outward conductance was blocked by TPMPA, indicating that it resulted from the activation of $\mathrm{GABA}_{\mathrm{C}}$ Rs (Fig. 1C3). In the presence of TPMPA, CTZ appeared to block minimally the presynaptic $\mathrm{Ca}^{2+}$ current, consistent with another study of retinal bipolar cells (von Gersdorff et al., 1998). Addition of TPMPA, however, did not alter the EPSC waveform in the presence of CTZ (Fig. 1C3) (percentage of CTZ alone: peak current $=109 \pm 4 \%$; EPSC integral $=104 \pm 21 \% ; n=3$ ).

As another way to examine the time course of transmission from RBCs, we made paired, voltage-clamp recordings from RBCs and postsynaptic A17 amacrine cells. Putative A17 amacrines were identified on the basis of their soma shape and position within the INL: large, dome-shaped somas with a flat edge abutting the border between the INL and IPL (Fig. $2 \mathrm{~A}$, left panel). When visualized after epi-illumination of injected fluorescent tracers, the A17 exhibited a characteristic morphology (Fig. 2A, right panel): a highly branched dendritic tree that extends over hundreds on micrometers through the IPL and receives synaptic input from hundreds of rod bipolar cells at varicosities on the distal ends of its fine dendrites (Nelson and Kolb, 1985; Menger and Wassle, 2000; Li et al., 2002; Zhang et al., 2002). Given the low density of distal varicosities in the large dendritic field of A17 amacrine cells, finding synaptically coupled RBC-A17 pairs was difficult. Additionally, the synaptic currents recorded at the soma likely were filtered by the cable properties of the long, thin dendrites of the A17s, making quantitative measurements of these currents difficult. The EPSCs recorded from four RBC-A17 pairs were quite small ( $12 \pm 3 \mathrm{pA}$ ), but they followed the same general time course as those recorded in AIIs $\left(Q T_{1 / 2}=19.8 \pm 8.3 \mathrm{msec}\right)$ (Fig. 2B). Additionally, like those recorded in AIIs, EPSCs in A17s were potentiated by CTZ (peak $=116 \pm 7 \%$ of control; integral $=221 \pm 94 \%$ of control; $n=3$ ). CTZ appeared to enhance the slow component more than the peak, but the general EPSC waveform was retained (Fig. 2C) (both picrotoxin and TPMPA were included in the external solution): $Q T_{1 / 2}=25.9 \pm$ $12.8 \mathrm{msec}$. The fact that both of the neurons postsynaptic to RBCs exhibit EPSCs with pronounced transient components after sustained presynaptic depolarization suggests that exocytosis from $\mathrm{RBC}$ terminals is primarily a transient process. Because of the difficulty of obtaining paired $\mathrm{RBC}-\mathrm{A} 17$ recordings, all subsequent experiments were performed using RBC-AII pairs only.

\section{$\mathrm{Ca}^{2+}$-permeable AMPARs mediate EPSCs}

Spontaneous EPSCs in AIIs are mediated by AMPARs (Veruki et al., 2003). Anatomical and electrophysiological studies suggest that these AMPARs are primarily of the $\mathrm{Ca}^{2+}$-permeable type: the glutamate receptor (GluR) subunits GluR3 and GluR4, but not GluR2, are found on AII amacrine cells at the RBC-AII synapse (Ghosh et al., 2001), and large-conductance, highly $\mathrm{Ca}^{2+}$ - 
A

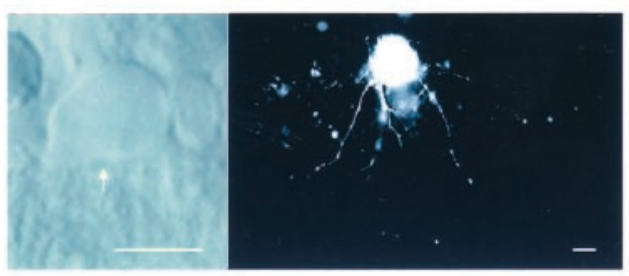

B
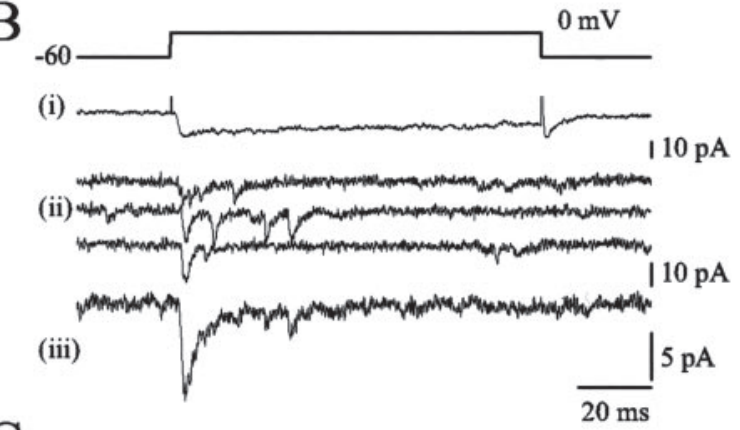

C

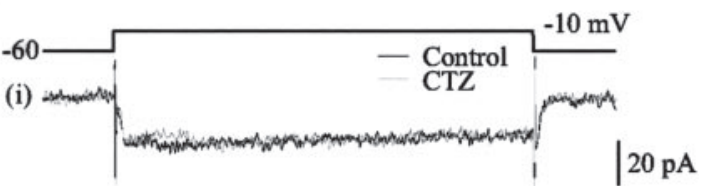

(ii)

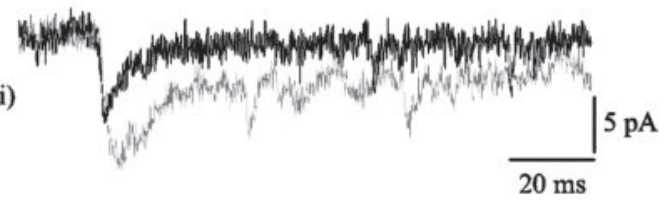

Figure 2. EPSCs recorded in A17s are transient. A, Left, DIC image showing characteristic morphology of an A17 amacrine cell soma. Right, Fluorescence image of an A17 amacrine cell, visualized by including Alexa 488 in the recording pipette. Scale bars: $A, B, 10 \mu \mathrm{m}$. $B$, Responses from an $\mathrm{RBC}-\mathrm{A} 17$ pair elicited by a $100 \mathrm{msec}$ voltage step to $0 \mathrm{mV}$ in the RBC. Picrotoxin and TPMPA were present in all solutions. i, Averaged, leak-subtracted presynaptic current. ii, Three consecutive, individual EPSCs recorded in the postsynaptic $A 17\left(V_{m}=-60 \mathrm{mV}\right)$. iii, Average of five EPSCs. C, Effects of CTZ on RBC-A17 synapses. I, Averaged, leak-subtracted presynaptic currents in control conditions (black trace) and in the presence of $50 \mu \mathrm{m}$ CTX (gray trace). ii, Averaged EPSCs $\left(V_{\mathrm{m}}=-90 \mathrm{mV}\right)$ in control conditions (black trace) and in the presence of CTZ (gray trace). Recordings are from a different pair than illustrated in $B$.

permeable AMPARs are observed in nucleated patches from AII somata (Morkve et al., 2002). Consistent with this, we found that including spermine $(150 \mu \mathrm{M})$ in the postsynaptic pipette induced inward rectification in the EPSC $I-V$ relationship (Fig. $3 A, B$ ), indicating that the AMPARs at RBC-AII synapses are indeed $\mathrm{Ca}^{2+}$ permeable (Jonas et al., 1994; Bowie and Mayer, 1995).

The evoked EPSCs were blocked at potentials between -80 and $+40 \mathrm{mV}$ both by AMPA/kainate receptor antagonists (either $25 \mu \mathrm{M}$ 6,7-dinitroquinoxaline-2,3-dione or $5 \mu \mathrm{M}$ 1,2,3,4-tetrahydro-6-nitro-2,3-dioxo-benzo[f] quinoxaline7 -sulfonamide): percentage of block $=98 \pm 1 \%$ at $-80 \mathrm{mV}$; $96 \pm 1 \%$ at $+40 \mathrm{mV}$ ( $n=4$ and 6 , respectively) and by an AMPAR antagonist, 1-(4-aminophenyl)-4-methyl-7,8-methylenedioxy-5H-2,3-benzodiazepine (GYKI-52466) (25 $\mu \mathrm{M})$ : $91 \pm 2 \%$ block at $-80 \mathrm{mV} ; 86 \pm 3 \%$ at $+40 \mathrm{mV}$ (Fig. $3 \mathrm{~A})(n=$ $7)$. Our observation that NMDA receptors do not contribute to EPSCs at this synapse is consistent with recent electrophysiological and anatomical studies (Hartveit and Veruki, 1997; Fletcher et al., 2000; Veruki et al., 2003).
A

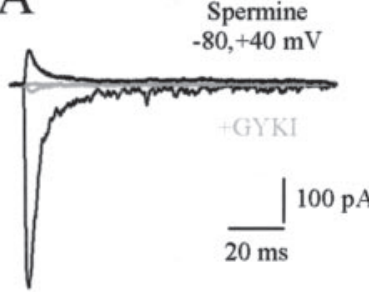

$\mathrm{C}$

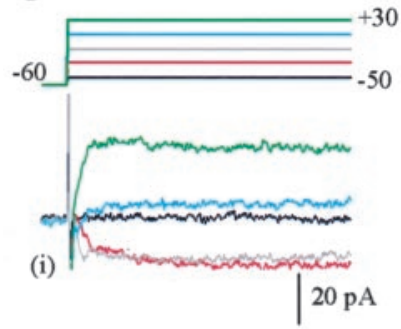

(ii)

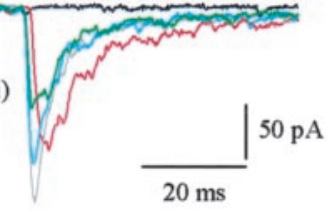

$\mathrm{E}$

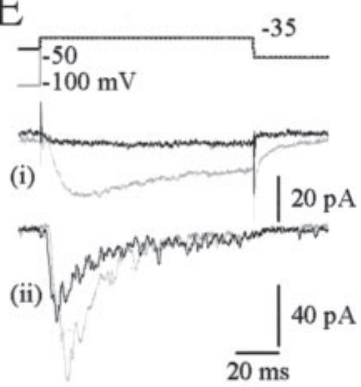

B

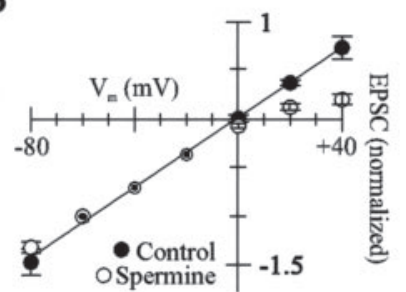

D1

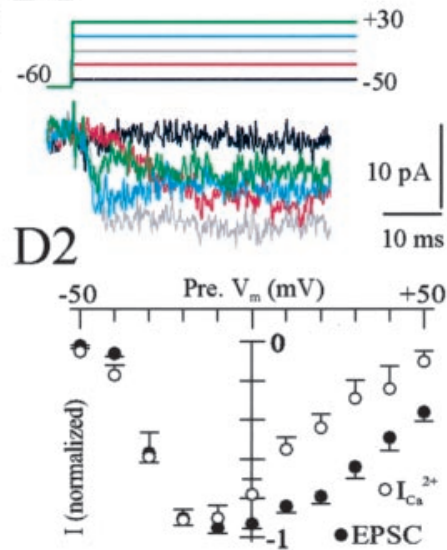

$\mathrm{F}$

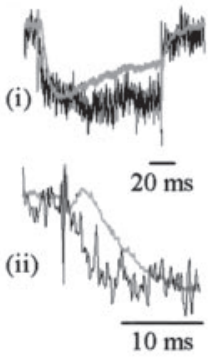

$\mathrm{G}$

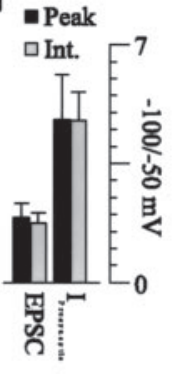

Figure 3. Presynaptic and postsynaptic characterization of the RBC-All synapse. A, EPSCs (evoked by $100 \mathrm{msec}$ steps from -60 to $0 \mathrm{mV}$ in the RBC) recorded at -80 and $+40 \mathrm{mV}$ with spermine $(150 \mu \mathrm{M})$ in the pipette are inwardly rectifying and blocked by GYKI-52466 (gray traces). $B$, Current-voltage relationships for EPSCs in control conditions $(\mathbf{O} ; n=6)$ and with spermine in the postsynaptic pipette $(\bigcirc ; n=10)$. EPSC amplitudes were normalized to that recorded at $-60 \mathrm{mV}$; the line reflects a linear fit to the control data. C, i, Presynaptic currents recorded with the standard $\mathrm{Cs}^{+}$-based internal solution and elicited by voltage steps of increasing amplitude ( -50 to $+30 \mathrm{mV}$ in $20 \mathrm{mV}$ increments) from $-60 \mathrm{mV}$. ii, EPSCs recorded in a synaptically coupled All $\left(V_{m}=-60 \mathrm{mV}\right)$. Different colors correspond to various presynaptic step potentials, as illustrated at the top of the panel. $\mathrm{D1}, \mathrm{Ca}^{2+}$ currents recorded with an $\mathrm{NMDG}^{+}$-based pipette solution. Currents were obtained by subtracting responses recorded in $100 \mu \mathrm{m} \mathrm{Cd}^{2+}$ from those in control. The color scheme is the same as in C. D2, Current-voltage relationship for the presynaptic $\mathrm{Ca}^{2+}$ current $\left(\bigcirc\right.$; recorded with $\mathrm{NMDG}^{+}$or $\mathrm{TMA}^{+}$internal solution; $n=5)$ and EPSCs evoked by the varying presynaptic voltage steps (-; recorded in different experiments with $\mathrm{Cs}^{+}$in the presynaptic internal solution; $\left.n=10\right)$. The EPS(s and $\mathrm{Ca}^{2+}$ currents are normalized to their respective maximum peak amplitudes. E, Contribution of T-type $\mathrm{Ca}^{2+}$ channels to release. i, Presynaptic currents evoked by steps to $-35 \mathrm{mV}$ from $V_{\mathrm{m}}=$ $-100 \mathrm{mV}$ (gray) or $-50 \mathrm{mV}$ (black). ii, EPSCs elicited by the same steps in an All $\left(V_{\mathrm{m}}=-90\right.$ $\mathrm{mV}) . F, \mathrm{~A}$ comparison of the waveforms of $\mathrm{Ca}^{2+}$ currents evoked by the voltage steps in $E$. i, Waveforms scaled to the same peak amplitude to illustrate contrasting inactivation. ii, Scaled waveforms on an expanded time scale to illustrate contrasting activation. G, Peak and integral of $\mathrm{Ca}^{2+}$ currents and EPSCs elicited by steps from $-100 \mathrm{mV}$ normalized to those elicited by steps from $-50 \mathrm{mV}$ to illustrate that the large, inactivating $\mathrm{Ca}^{2+}$ current enhances glutamate release from the presynaptic terminal $(n=7)$. 


\section{The $I_{\mathrm{Ca}}{ }^{2+}$-EPSC relationship}

To explore the relationship between presynaptic $\mathrm{Ca}^{2+}$ entry and vesicle release at this synapse, we stepped RBCs from a $V_{\mathrm{m}}$ of -60 $\mathrm{mV}$ to different step potentials in $10 \mathrm{mV}$ increments for $50-100$ msec to evoke EPSCs in AIIs $\left(V_{\mathrm{m}}=-60 \mathrm{mV}\right.$ ) (Fig. $3 C$ ) (responses to steps of $20 \mathrm{mV}$ increments are illustrated for clarity). The activation threshold for both presynaptic $I_{\mathrm{Ca}}{ }^{2+}$ and EPSCs was near $-40 \mathrm{mV}$ (Fig. $3 C, D$, closed circles) $(n=10$ pairs). The EPSC amplitude was steeply dependent on presynaptic potentials in the range of -40 to $-20 \mathrm{mV}$, the physiological operating range of RBCs (Euler and Masland, 2000), and it was maximal after presynaptic steps to $-10 \mathrm{mV}(169 \pm 5 \mathrm{pA} n=10)$. This steep "synaptic gain" also has been noted in studies of isolated goldfish Mixed bipolar 1 (Mb1) bipolar cell terminals (von Gersdorff et al., 1998).

Although the pipette solution for $\mathrm{RBC}$ recordings contained both $\mathrm{Cs}^{+}$and $\mathrm{TEA}^{+}$to block $\mathrm{K}^{+}$channels, the presynaptic membrane current exhibited an $E_{\text {rev }}$ of $\sim 0 \mathrm{mV}$ (Fig. 3C, i). This $E_{\text {rev }}$ is more negative than would be expected for a pure $\mathrm{Ca}^{2+}$ conductance, suggesting that the presynaptic $\mathrm{Ca}^{2+}$ currents were contaminated, possibly by $\mathrm{Cs}^{+}$passing through $\mathrm{K}^{+}$channels or by a $\mathrm{Ca}^{2+}$-dependent $\mathrm{Cl}^{-}$current; similar observations have been made in other studies of RBCs (Okada et al., 1995; Protti and Llano, 1998; Hartveit, 1999). To determine more precisely the current-voltage relationship for the $\mathrm{Ca}^{2+}$ current, we recorded from five RBCs using an internal solution in which $\mathrm{NMDG}^{+}$or $\mathrm{TMA}^{+}$was substituted for Cs ${ }^{+}$(Fig. 3D1) (during one of these experiments, EPSCs were recorded from a postsynaptic AII amacrine, and the EPSCs exhibited the characteristic waveform and presynaptic voltage dependence of EPSCs at this synapse). In these neurons, membrane currents elicited by voltage steps from $-60 \mathrm{mV}$ were blocked almost completely by 100 $\mu \mathrm{M} \mathrm{Cd}^{2+}$ (data not shown). $\mathrm{Ca}^{2+}$ currents in the RBCs activated between -50 and $-40 \mathrm{mV}$ were maximal at $-20 \mathrm{mV}$ (peak amplitude $=16 \pm 2 \mathrm{pA}$ ) and remained inward at $+50 \mathrm{mV}$. The EPSC current versus presynaptic step potential relationship mirrored that of the $I_{\mathrm{Ca}}{ }^{2+}$, particularly in the voltage range between -40 and $-20 \mathrm{mV}$ (Fig. 3D2, open circles). Recordings with $\mathrm{NMDG}^{+}$- and $\mathrm{TMA}^{+}$-based internal solutions, however, were less stable than those in which $\mathrm{Cs}^{+}$was the primary cation. Consequently, we chose to use the $\mathrm{Cs}^{+}$-based internal solution for our experiments; as a result, the presynaptic currents illustrated in the figures other than Figure 3D1 may not be pure $\mathrm{Ca}^{2+}$ currents.

The $\mathrm{Ca}^{2+}$ currents that we recorded in RBCs did not appear to inactivate substantially during the $100 \mathrm{msec}$ step. This, together with their $I-V$ relationship (Fig. 3D2), indicates that they reflect $\mathrm{Ca}^{2+}$ influx through L-type $\mathrm{Ca}^{2+}$ channels (Rosenberg et al., 1988). Fluorescent $\mathrm{Ca}^{2+}$-indicator imaging (Protti and Llano, 1998), electrophysiological recordings (Hartveit, 1999; Pan, 2000; Pan, 2001), and immunohistochemical methods (Satoh et al., 1998) have demonstrated that sustained $\mathrm{Ca}^{2+}$ currents recorded in mammalian RBCs are mediated by L-type $\mathrm{Ca}^{2+}$ channels located in axon terminals. We conclude, then, that the $\mathrm{Ca}^{2+}$ current that we recorded in the RBC somas arose from the $\mathrm{Ca}^{2+}$ influx driving neurotransmitter release from the axon terminal.

Low voltage-activated, transient $\mathrm{Ca}^{2+}$ currents also have been observed in RBCs (Hartveit, 1999; Pan, 2000; Pan et al., 2001) (but see Protti and Llano, 1998), and $\mathrm{Ca}^{2+}$ influx through T-type $\mathrm{Ca}^{2+}$ channels can trigger exocytosis from RBC terminals (Pan et al., 2001). Although we saw no evidence for activation of a transient current after voltage steps from $V_{\mathrm{m}}=-60 \mathrm{mV}$, we wished to determine how such a current could contribute to transmis- sion at the RBC-AII synapse. To do so, we stepped the RBCs from -60 to either $-100 \mathrm{mV}$ for $1 \mathrm{sec}$ to allow $\mathrm{T}$-channels to recover fully from inactivation or to $-50 \mathrm{mV}$ to inactivate them completely and then to $-35 \mathrm{mV}$ (the half-maximal activation potential for the channels) (Pan, 2000) for $100 \mathrm{msec}$ (Fig. 3E). These experiments were performed in the presence of picrotoxin and TPMPA. The $\mathrm{Ca}^{2+}$ current after the $100 \mathrm{mV}$ prepulse resembled the T-type $\mathrm{Ca}^{2+}$ channel-mediated currents in RBCs described by others (Pan et al., 2001). The transient currents were almost four times larger $(37 \pm 5$ vs $10 \pm 3 \mathrm{pA} ; p=0.001 ;-100 \mathrm{mV}$ prepulse vs $-50 \mathrm{mV}$ prepulse) and activated more slowly than sustained currents (Fig. $3 F)(n=7)$. Additionally, the integral of the transient current was $478 \pm 132 \%$ of the sustained current $(p=0.018)$ (Fig. 3G).

Because T-type $\mathrm{Ca}^{2+}$ channels in RBCs activate slowly (Fig. 3F) (Pan et al., 2001), the EPSC 10-90\% rise time was slower after the prepulse $(8.3 \pm 1.9 \mathrm{msec}$ vs $6.3 \pm 1.8 \mathrm{msec}$ with no prepulse; $p=0.001 ; n=7)$. Additionally, in six of seven experiments, the EPSCs recorded in AII amacrine cells were larger after the prepulse to $-100 \mathrm{mV}$ (Fig. $3 E$ ). When all seven recorded pairs were considered, the EPSC amplitude was increased to $191 \pm$ $43 \%(p=0.1)$, and the EPSC integral was increased to $175 \pm$ $30 \%(p=0.13)$ of that evoked by a voltage step from $-50 \mathrm{mV}$ (Fig. 3G). When the one cell in which the EPSC amplitude did not change was excluded from the analysis, the changes in EPSC amplitude $(209 \pm 46 \%)$ and integral $(189 \pm 33 \%)$ were statistically significant $(p=0.049$ and 0.0025 for the changes in amplitude and integral, respectively). We conclude, then, that T-type $\mathrm{Ca}^{2+}$ channels in the RBC axon terminal can boost glutamatergic neurotransmission at RBC synapses. It does not appear, however, that activation of T-channels is required to make the EPSCs transient.

\section{Release rate varies with $\mathrm{Ca}^{2+}$ influx}

When evoked by presynaptic voltage steps to -10 or $0 \mathrm{mV}$, the waveforms of EPSCs recorded in AIIs were dominated by the initial, fast component (Fig. 1). RBCs, however, are not depolarized to this extent by light stimuli (Berntson and Taylor, 2000; Euler and Masland, 2000), raising the possibility that EPSCs may be transient only when release is elicited by nonphysiological levels of presynaptic depolarization. To address this issue, we evoked EPSCs in AIIs by stepping the presynaptic RBCs from $-60 \mathrm{mV}$ to the most hyperpolarized membrane potential at which release was evident: approximately $-40 \mathrm{mV}$, a value that varied among RBCs (Fig. 4A). Using this approach in nine RBCAII pairs, we activated small presynaptic $\mathrm{Ca}^{2+}$ currents that evoked small EPSCs (peak amplitude $=20 \pm 4 \mathrm{pA}$ ). These EPSCs were slower than those evoked by presynaptic voltage steps to $-10 \mathrm{mV}(10-90 \%$ rise time $=9.8 \pm 2.6 \mathrm{msec})$, but they still exhibited a transient component: $Q T_{1 / 2}=36.5 \pm 2.6 \mathrm{msec}$. Taken together with the observation that EPSCs evoked by steps from -50 to $-35 \mathrm{mV}$ exhibit a large transient component (Fig. $3 E$ ), this experiment suggests that no matter what the level of depolarization, most of the release from RBCs in response to a $100 \mathrm{msec}$ step occurs in the first $50 \mathrm{msec}$.

Because the level of presynaptic depolarization affects the waveform of the EPSC, we examined the RBC-AII recordings summarized in Figure 3D2 in more detail (these data were acquired from different RBC pairs than those represented by Fig. $4 A$ ). The EPSCs evoked by depolarizing steps to $0 \mathrm{mV}$ were faster than those evoked by steps to $-30 \mathrm{mV}$ (Fig. 4B) $(n=9): 10-90 \%$ rise time $=1.3 \pm 0.1$ vs $3.7 \pm 0.8 \mathrm{msec}(p=0.017) ; Q T_{1 / 2}=$ $10.2 \pm 1.1$ vs $21.6 \pm 2.2 \mathrm{msec}(p=0.004)$. These differences 
A

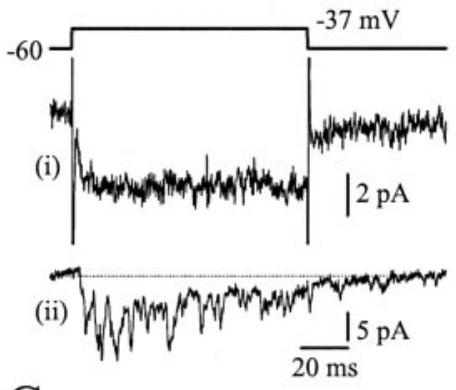

$\mathrm{C}$

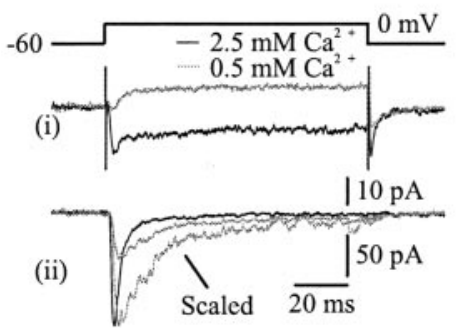

B
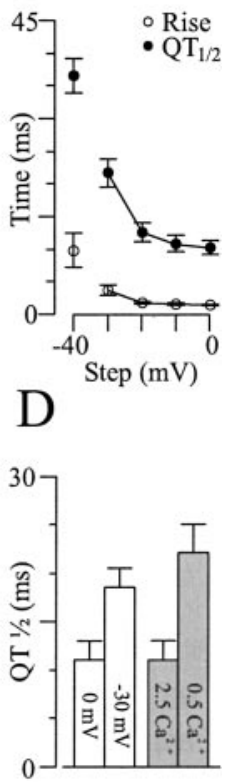

Figure 4. Release rate varies with $\mathrm{Ca}^{2+}$ influx. $A, \mathrm{i}$, Presynaptic current elicited by a presynaptic 100 msec voltage step from -60 to $-37 \mathrm{mV}$. ii, Averaged EPSC recorded in a synaptically coupled All $\left(V_{\mathrm{m}}=-90 \mathrm{mV}\right)$. B, Average $10-90 \%$ rise times $(O)$ and $Q T_{1 / 2}(O)$ of EPSCs evoked by stepping the $R B C$ to approximately $-40 \mathrm{mV}$ or to potentials between -30 and $0 \mathrm{mV}$ (the data in the $-40 \mathrm{mV}$ point comes from separate RBC-All pairs, as indicated by the fact that it is not joined to the other points, but $n=9$ for both sets of data). C, i, Presynaptic currents elicited in control (black) or low $\left[\mathrm{Ca}^{2+}\right]$ (gray) conditions. ii, EPSCs evoked in a synaptically coupled All $\left(V_{m}=-60 \mathrm{mV}\right)$. The EPSC in low $\left[\mathrm{Ca}^{2+}\right]$ is scaled to control for comparison. The $\mathrm{RBC}$ membrane current is outward in $0.5 \mathrm{~mm} \mathrm{Ca}^{2+}$ because a small $\mathrm{Ca}^{2+}$ current is contaminated by an outward conductance. $D$, Summary $Q T_{1 / 2}$ values for EPSCs elicited by presynaptic steps to -30 and $0 \mathrm{mV}$ (white bars; $n=9$ ) and in normal and low $\mathrm{Ca}^{2+}$ (gray bars; $\left.n=9\right)$.

suggest that the highest rates at which exocytosis can occur, as reflected by the relative contribution of the fastest component of the EPSC, require high intracellular $\left[\mathrm{Ca}^{2+}\right]$. Consistent with this, when extracellular $\left[\mathrm{Ca}^{2+}\right]$ was reduced, EPSCs were slower (Fig. 4C): $Q T_{1 / 2}$ increased from $11.3 \pm 2.2 \mathrm{msec}$ in $2.5 \mathrm{mM}\left[\mathrm{Ca}^{2+}\right]$ to $21.6 \pm 2.7 \mathrm{msec}$ in $0.5 \mathrm{~mm}\left[\mathrm{Ca}^{2+}\right.$ ] (Fig. $\left.4 D\right)(n=9, p=0.008)$. Taken together, the experiments described here indicate that the initial transient component of the EPSC is a sensitive indicator of the rate of presynaptic $\mathrm{Ca}^{2+}$ influx.

\section{Tail $\mathrm{Ca}^{2+}$ currents evoke fast EPSCs}

The speeding of the EPSC rise time with increasing presynaptic depolarization suggests that presynaptic $\mathrm{Ca}^{2+}$ channel activation limits the rise of the EPSC. To determine how quickly the RBC terminal would release vesicles if $\mathrm{Ca}^{2+}$ entry were not delayed by $\mathrm{Ca}^{2+}$ channel activation, we evoked EPSCs with presynaptic $\mathrm{Ca}^{2+}$ tail currents [see also Mennerick and Matthews (1996) and von Gersdorff et al. (1998)]. Stepping the RBC from -60 to +90 $\mathrm{mV}$ for $10-100 \mathrm{msec}$ did not elicit a response in the AII (Fig. $5 \mathrm{~A}$ ), presumably because $+90 \mathrm{mV}$ is near $E_{\mathrm{Ca}}{ }^{2+}$. After repolarization, $\mathrm{Ca}^{2+}$ influx, reflected by a tail current, evoked an EPSC (tEPSC) that rose and fell rapidly (Fig. 5A). Step-evoked EPSCs and tEPSCs had similar amplitudes: $181 \pm 15 \mathrm{pA}$ vs $197 \pm 16$ (Fig. $5 C)(n=29, p=0.0004)$, suggesting that the peak of the stepevoked EPSC and the tEPSC reflect the release of the same immediately releasable pool of vesicles. The tEPSC rise time was faster, however, than that of the step-evoked EPSC: $0.7 \pm 0.03$ vs $1.3 \pm$ $0.1 \mathrm{msec}$ (Fig. $5 C)(n=29, p<0.0001)$, supporting the suggestion that $\mathrm{Ca}^{2+}$ channel activation limits the rate of exocytosis, as

A
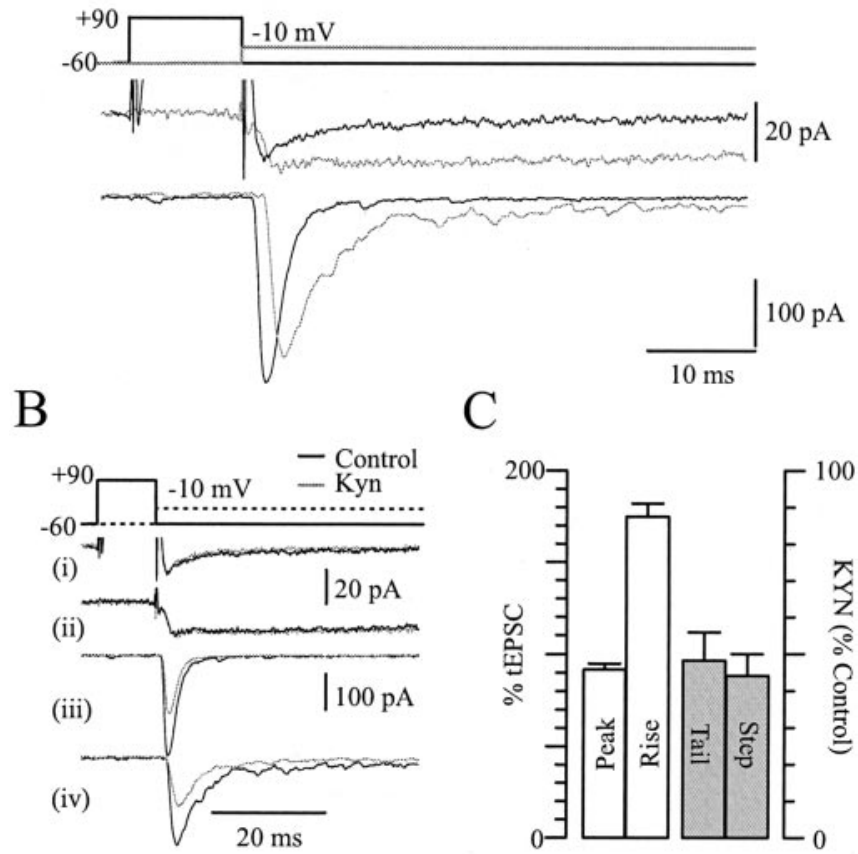

$\mathrm{D}$

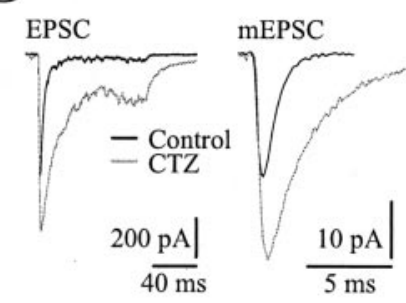

E

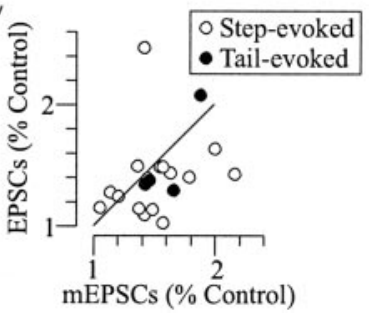

Figure 5. Rapid presynaptic $\mathrm{Ca}^{2+}$ entry evokes fast tEPSCs. A, i, Presynaptic currents elicited by a step from +90 to $-60 \mathrm{mV}$ (black trace) or from -60 to $-10 \mathrm{mV}$ (gray trace). ii, EPSCs $\left(V_{\mathrm{m}}=-90 \mathrm{mV}\right)$ recorded in a synaptically coupled All. Note that the presynaptic step from -60 to $+90 \mathrm{mV}$ elicits no postsynaptic response. B, Effects of $250 \mu \mathrm{m}$ KYN (gray traces) on the presynaptic tail current (i), the presynaptic step-evoked current (ii), tEPSC (iii), and step-evoked EPSC (iv). Responses are from the same RBC-All pair as in A. C, Summary comparison of amplitude and rise time of step-evoked EPSCS normalized to those of the tEPSC recorded in the same cell (open bars; $n=29$ ). Summary effects of KYN (as a percentage of control) on the amplitudes of step-evoked EPSCs and tEPSCs $(n=5)$. D, Average EPSCs or mEPSCs recorded in an All $\left(V_{\mathrm{m}}=\right.$ $-90 \mathrm{mV}$ ) in the absence (black) or presence (gray) of CTZ $(50 \mu \mathrm{M})$. E, Summary comparison of the effect of CTZ (as a percentage of control) on EPSC and mEPSC amplitude. Data from 20 recorded pairs are shown ( $n=16$ for step-evoked EPSCs; $n=4$ for tEPSCs). Diagonal line indicates unity.

observed with capacitance measurements in goldfish Mb1 terminals (Mennerick and Matthews, 1996).

If the peaks of the tEPSC and the step-evoked EPSC reflect the release of a similar number of vesicles, then the cleft glutamate concentrations giving rise to both should be comparable. To test this prediction, we examined the effects of a low concentration of kyneurenic acid (KYN) $(250 \mu \mathrm{M})$, a rapidly dissociating AMPAR antagonist, on step-evoked EPSCs and tEPSCs. The extent to which KYN blocks synaptic currents depends on cleft neurotransmitter concentration (Clements et al., 1992; Diamond and Jahr, 1997). Consequently, if the peak amplitude of tEPSCs and step-evoked EPSCs reflects the release of substantially different amounts of glutamate, the two currents should be affected differentially by KYN, even if the postsynaptic receptors are saturated. As illustrated in Figure 5B, however, KYN had similar effects on 
the EPSCs, blocking the tEPSC to $48 \pm 8 \%$ of control and the step-evoked EPSC to $44 \pm 6 \%$ of control [KYN block of tEPSC vs step-evoked EPSC; $p=0.5$ (paired $t$ test); $n=5$ ] (Fig. $5 C$, gray bars), indicating that a comparable amount of glutamate release contributes to the peak response in both cases.

It is possible, however, that KYN had equivalent effects on tEPSCs and step-evoked EPSCs because the postsynaptic AMPARs were saturated by synaptically released glutamate. A closer examination of the effects of CTZ on EPSCs, however, argues against this possibility. As noted, CTZ increased the amplitude of stepevoked EPSCs, an effect likely attributable to an enhancement of AMPAR affinity rather than the abolition of fast desensitization (Partin et al., 1993), because the EPSC rise time is faster than the reported time constant for desensitization of AMPARs on AIIs ( $<2$ vs $\sim 7 \mathrm{msec}$ ) (Veruki et al., 2003). CTZ exerted similar effects on the amplitudes of step-evoked EPSCs and spontaneous, miniature EPSCs (mEPSCs), which rise even more rapidly [mEPSC $10-90 \%$ rise time $=0.38 \pm 0.2 \mathrm{msec}$; in CTZ, EPSC and mEPSC amplitudes were $139 \pm 9$ and $151 \pm 8 \%$ of control, respectively; $n=16 ; p=0.24$ (paired $t$ test)] (Fig. 5E). In a separate set of recordings, CTZ also potentiated $\mathrm{mEPSC}$ and $\mathrm{tEPSC}$ amplitudes similarly [percentage of control current: $152 \pm 21 \%$ for tEPSC and $161 \pm 12 \%$ for mEPSC; $n=4 ; p=0.52$ (paired $t$ test)] (Fig. $5 E)$. Together, these data indicate that because increasing AMPAR affinity with CTZ increases postsynaptic current amplitude, postsynaptic receptors likely are not saturated by glutamate at this synapse.

Asynchronous release is enhanced when terminal $\mathrm{Ca}^{2+}$ buffer capacity is reduced

Given the $\mathrm{Ca}^{2+}$ dependence of the step-evoked EPSC waveform (Fig. 4), we considered the possibility that release events occur at varying distances from the site of calcium entry. For example, the fast component of the EPSC may reflect exocytosis triggered by high $\left[\mathrm{Ca}^{2+}\right]$ at the mouth of presynaptic $\mathrm{Ca}^{2+}$ channels, and the slower, more sustained component may reflect release driven by steady-state intraterminal $\left[\mathrm{Ca}^{2+}\right]$. If this were the case, the later portion of the EPSC should be potentiated preferentially by lowering the intraterminal buffer concentration. To test this prediction, we recorded from RBC-AII pairs with $0.2 \mathrm{~mm}$ EGTA in the presynaptic (whole-cell) recording pipette and compared the EPSCs with those evoked when 10 mm EGTA or 1.5 mm BAPTA was included in the pipette solution or during perforated-patch recordings (Fig. 6A-D).

Dual-component EPSCs persisted when the terminal $\mathrm{Ca}^{2+}$ buffering capacity was changed (Fig. $6 A-D$ ). The EPSC rise time was unaffected by manipulating exogenous $\mathrm{Ca}^{2+}$ buffers (values for $0.2 \mathrm{~mm}$ EGTA, $10 \mathrm{~mm}$ EGTA, 1.5 BAPTA, and perforatedpatch, respectively): $10-90 \%$ rise time $=1.2 \pm 0.1,1.3 \pm 0.2$, $1.3 \pm 0.1$, and $1.2 \pm 0.1 \mathrm{msec}(p=0.99$ by ANOVA), and the $\tau_{\text {decay }}$ of the fast component also was unchanged (single exponential fit to the first $25 \mathrm{msec}$ after the EPSC peak): $4.2 \pm 0.2,4.2 \pm$ $0.6,4.0 \pm 0.3$, and $4.1 \pm 0.3 \mathrm{msec}(p=0.96$ by ANOVA). The EPSC amplitude tended to be larger in the $0.2 \mathrm{~mm}$ EGTA condition (recordings were made at a postsynaptic $V_{\mathrm{m}}$ of either -60 or $-90 \mathrm{mV}$; EPSC amplitudes recorded at $-60 \mathrm{mV}$ were multiplied by 1.5 to scale them to those recorded at $-90 \mathrm{mV}$ ): $400 \pm 56$, $274 \pm 55,290 \pm 42$, and $252 \pm 60 \mathrm{pA}$, although these differences were not statistically significant ( $p=0.21$ by ANOVA).

$Q T_{1 / 2}$ was largest in the $0.2 \mathrm{~mm}$ EGTA condition: $18.0 \pm 1.4$, $11.3 \pm 1.5,14.3 \pm 1.4$, and $9.4 \pm 1.1 \mathrm{msec}(0.2 \mathrm{~mm}$ EGTA, $10 \mathrm{~mm}$ EGTA, 1.5 BAPTA, and perforated patch; $p=0.002$ by ANOVA). This effect coincided with greatly enhanced asynchronous release
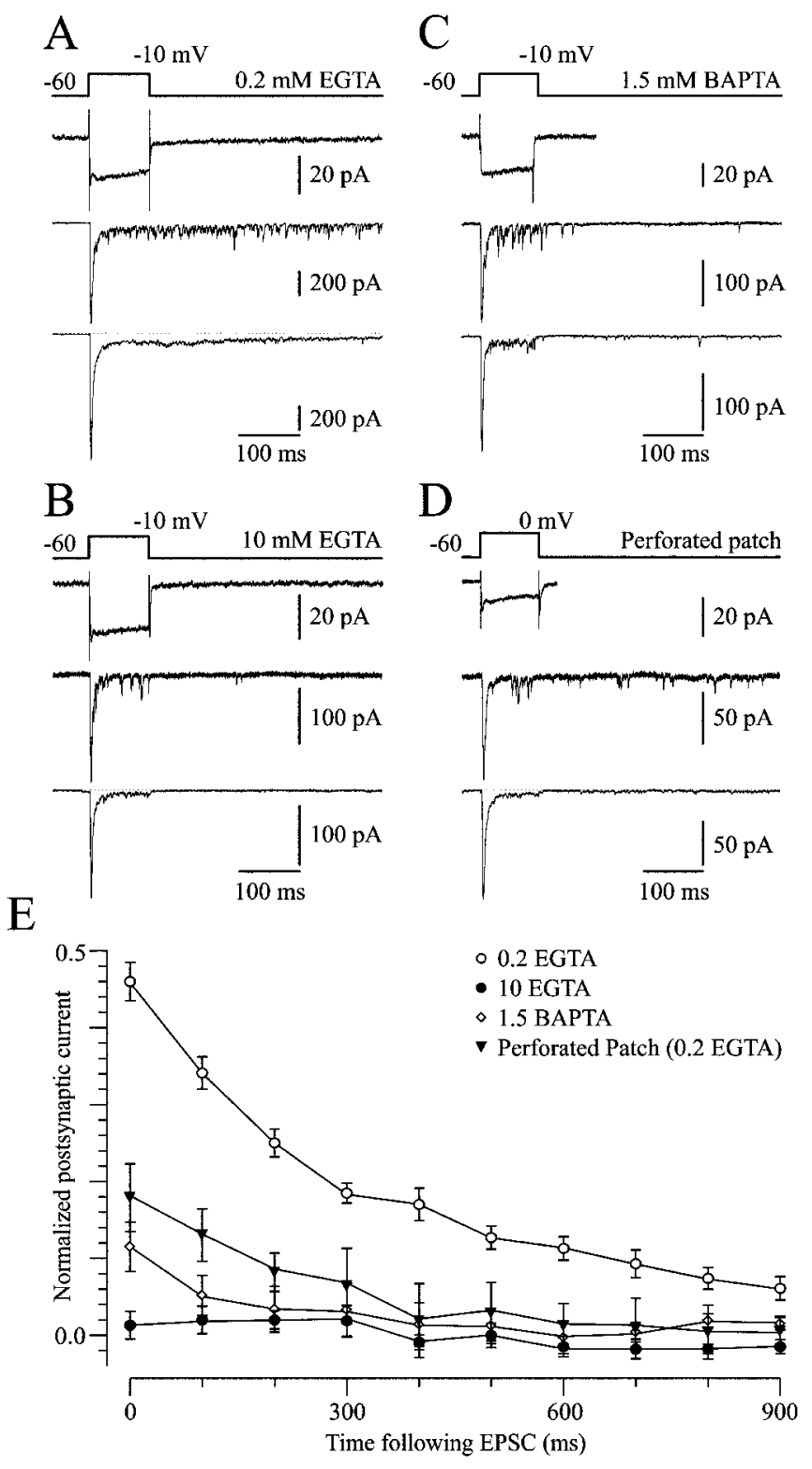

Figure 6. Endogenous $\mathrm{Ca}^{2+}$ buffering reduces asynchronous release. $A$, Presynaptic currents, a single EPSC, and an averaged EPSC recorded in an RBC-All pair with $0.2 \mathrm{~mm}$ EGTA in the presynaptic pipette. The All $V_{\mathrm{m}}=-60 \mathrm{mV}$. B, As in $A$ but with $10 \mathrm{~mm}$ EGTA in the presynaptic pipette. The All $V_{\mathrm{m}}=-60 \mathrm{mV}$. C, As in $A$ but with $1.5 \mathrm{~mm}$ BAPTA in the presynaptic pipette. The All $V_{\mathrm{m}}=-90 \mathrm{mV}$, and the presynaptic current trace is truncated because the steps for $\mathrm{P} / 4$ leak subtraction are blanked out. $D$, As in $A$ but with a perforated patch (Amphotericin B) recording from the $R B C$. The All $V_{m}=-60 \mathrm{mV}$, and, again, the presynaptic $P / 4$ responses are blanked. $E$, Summary comparison of asynchronous release in $0.2 \mathrm{~mm} \mathrm{EGTA}(n=22), 10 \mathrm{~mm} \operatorname{EGTA}(n=5)$, 1.5 mм BAPTA $(n=24)$, and perforated patch $(n=10)$. The postsynaptic current was integrated in 100 msec bins beginning 10 msec after the presynaptic voltage step, and the integral of each bin was normalized to that of the EPSC coinciding with the voltage step.

in the $0.2 \mathrm{~mm}$ EGTA condition that lasted hundreds of milliseconds after presynaptic $I_{\mathrm{Ca}}{ }^{2+}$ deactivation (Fig. 6A) $(n=22)$. Asynchronous release was reduced significantly (compared with 0.2 EGTA recordings) during whole-cell recordings with $1.5 \mathrm{~mm}$ BAPTA in the pipette (Fig. $6 C)(n=24)$ or during perforatedpatch recordings with $0.2 \mathrm{~mm}$ EGTA in the pipette solution (Fig. $6 D)(n=10)$. Asynchronous release was abolished altogether during recordings with $10 \mathrm{~mm}$ EGTA in the pipette (Fig. $6 \mathrm{~B})(n=$ 5 ), suggesting that it is driven by elevated residual intraterminal $\left[\mathrm{Ca}^{2+}\right]$ (Barrett and Stevens, 1972). These results are consistent 
A
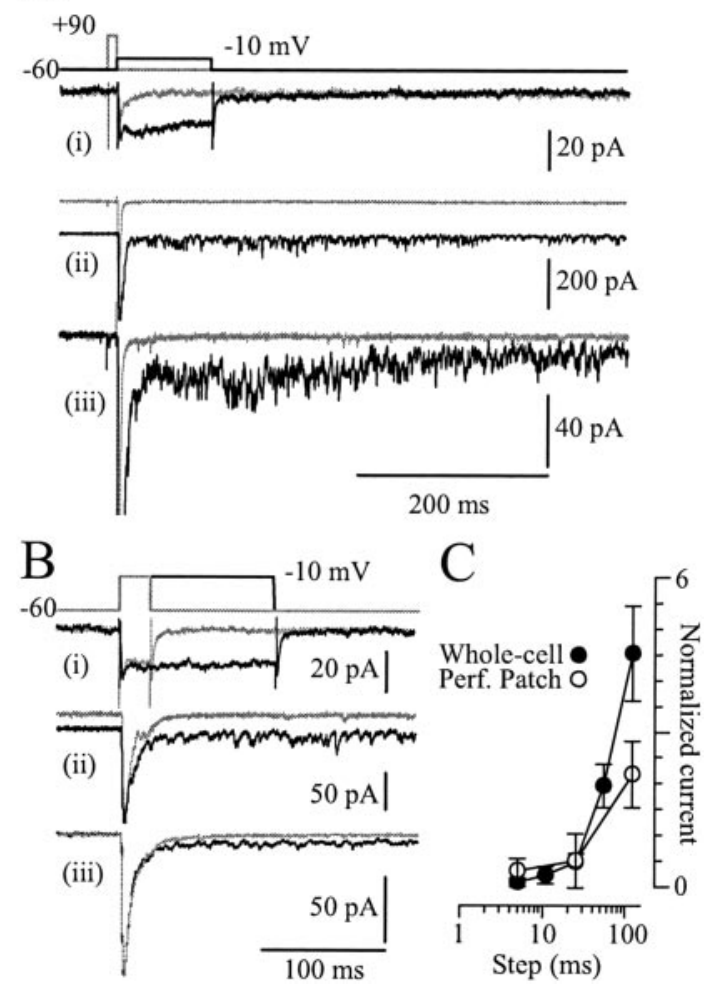

Figure 7. Time course of asynchronous release. $\mathrm{A}_{,} \mathrm{Ca}^{2+}$ currents (i) (tail $=$ gray, step $=$ black) and EPSCs (single responses in ii, offset for clarity; averages of 7 responses in iii) evoked with $0.2 \mathrm{~mm}$ EGTA in the presynaptic pipette. The peak of the average EPSCs in iii is truncated to magnify the asynchronous portion of the postsynaptic current. Asynchronous release is not evident in tEPSCs (gray traces). B, Voltage steps of $25 \mathrm{msec}$ (to $-10 \mathrm{mV}$ ) do not evoke asynchronous release [gray traces: presynaptic current (i), single postsynaptic responses (ii), and average of 7 responses (iii)], but 125 msec voltage steps do (black traces). C, The relationship between the length of the presynaptic depolarization and asynchronous release when the presynaptic RBC was recorded in either the whole-cell $(\mathbf{O} ; n=7$ RBC-All pairs) or the perforated-patch configuration $(\bigcirc ; n=6 \mathrm{RBC}$-All pairs) with $0.2 \mathrm{~mm}$ EGTA in the pipette solution. The postsynaptic current was integrated over a 1 sec interval beginning 25 msec after the presynaptic voltage step and normalized to the integral of the EPSC evoked by a 5 msec step.

with capacitance measurements from the terminals of isolated rat bipolar cells that revealed long-lasting, slow capacitance increases after presynaptic $\mathrm{Ca}^{2+}$ currents when the pipette solution contained $0.5 \mathrm{~mm}$, but not $5 \mathrm{~mm}$, EGTA (Pan et al., 2001).

We quantified asynchronous release by integrating the average postsynaptic current in $100 \mathrm{msec}$ bins (beginning $10 \mathrm{msec}$ after the presynaptic voltage step) and normalizing the integrals to that of the EPSC (Fig. 6 E). To reduce contamination of evoked responses by spontaneous activity, we integrated $100 \mathrm{msec}$ of the baseline current and subtracted this value from each bin. In addition, some experiments were performed in the presence of 2-amino-4-phosphonobutyric acid (L-AP4) (2.5 $\mu \mathrm{M})$, a metabotropic glutamate receptor agonist that hyperpolarizes ON bipolar cells (Slaughter and Miller, 1981) and reduced the frequency of mEPSCs recorded in AIIs (interevent interval increased from $64 \pm 8$ to $217 \pm 64 \mathrm{msec} ; n=6$ cells; data not shown) without altering mEPSC amplitude or waveform (percentage of control: amplitude $=100 \pm 3 \% ; 10-90 \%$ rise time $=101 \pm 2 \% ; \tau_{\text {decay }}=$ $103 \pm 4 \%)$. Asynchronous release was similar in the presence or absence of L-AP4, suggesting that averaging traces and subtracting the baseline minimized contamination by spontaneous activity; experiments in the presence and absence of L-AP4 therefore were pooled.
Asynchronous release did not follow tEPSCs, even when the pipette solution contained $0.2 \mathrm{~mm}$ EGTA (Fig. $7 A)(n=14)$, suggesting that the conditions permitting delayed release take time to develop. To test this hypothesis, we examined the postsynaptic responses to lengthening presynaptic voltage steps from 5 to $125 \mathrm{msec}$ (with $0.2 \mathrm{~mm}$ EGTA in the presynaptic pipette). Asynchronous release was measured as the integral of the postsynaptic current over a $1 \mathrm{sec}$ interval beginning $25 \mathrm{msec}$ after the presynaptic voltage was returned to $-60 \mathrm{mV}$ (this value was normalized to the integral of the EPSC evoked by a 5 msec step). Delayed release was not evident until the presynaptic voltage step exceeded $25 \mathrm{msec}$ (Fig. $7 B$, summarized in $C$, filled circles) $(n=$ 7). Asynchronous release appeared with a similar time course, although to a lesser extent, when presynaptic recordings were made in the perforated-patch configuration (Fig. 7C, open circles) ( $n=6$; asynchronous release differs between perforatedpatch and whole-cell recordings after 125 msec steps: $p=0.05$ by ANOVA). Asynchronous release did not increase further when the presynaptic step was lengthened to $625 \mathrm{msec}$ during perforated-patch recordings (data not shown; 125 vs $625 \mathrm{msec}$; $p=0.44 ; n=6$ ), indicating that the $\mathrm{Ca}^{2+}$ buffers and clearance mechanisms that set the residual intraterminal $\left[\mathrm{Ca}^{2+}\right]$ reach equilibrium after $\sim 125 \mathrm{msec}$.

RBCs are small neurons, but their thin axons are $\sim 60 \mu \mathrm{m}$ long (Euler and Wassle, 1995; Hartveit, 1997) and therefore may impede movement of molecules introduced through the patch electrode from the soma to the axon terminal. To estimate how long it takes exogenous buffers to reach the presynaptic terminal, we included $10 \mathrm{~mm}$ BAPTA in the presynaptic pipette during paired RBC-AII recordings in which we evoked tEPSCs and EPSCs alternately at $17 \mathrm{sec}$ intervals. This concentration of exogenous BAPTA caused a rapid reduction in the peak amplitude of both the tEPSC and the EPSC (Fig. 8A), such that both were eliminated almost completely in $360 \mathrm{sec}$ (Fig. $8 C)(n=5)$. A single exponential function fit to the pooled tEPSC and EPSC amplitudes yielded a $\tau=125 \mathrm{sec}$. When the same experiment was performed with $10 \mathrm{~mm}$ EGTA rather than BAPTA in the presynaptic pipette, the tEPSC and EPSC amplitudes remained stable for this same duration (Figs. $8 B, C)(n=5)$. The block of the EPSCs by $10 \mathrm{~mm}$ BAPTA introduced via a somatic recording electrode indicated that high concentrations of buffer can be achieved in the synaptic terminals in $\sim 2 \mathrm{~min}$, the time that passed between the establishment of a whole-cell recording from an $\mathrm{RBC}$ and the beginning of presynaptic stimulation during most of our experiments. Consequently, we conclude that the concentration of exogenous chelator in the terminal is similar to that in the pipette solution.

\section{Discussion}

Our results support three conclusions about transmission at mammalian RBC synapses. (1) Release kinetics are so fast that the EPSC rise time is limited by $\mathrm{Ca}^{2+}$ channel activation; (2) the EPSC exhibits a transient component in the absence of inhibitory feedback and receptor desensitization and appears to reflect an intrinsic decrease in release rate; and (3) endogenous $\mathrm{Ca}^{2+}$ buffers curtail exocytosis to a large extent soon after $\mathrm{Ca}^{2+}$ channel deactivation.

\section{Electrical access to the RBC terminal}

Despite the electrotonic barrier imposed by the axon between the somatic recording electrode and the $\mathrm{Ca}^{2+}$ conductance in the $\mathrm{RBC}$ terminal, three points suggest that our presynaptic voltage clamp is adequate. First, Protti and Llano (1998) showed that the 


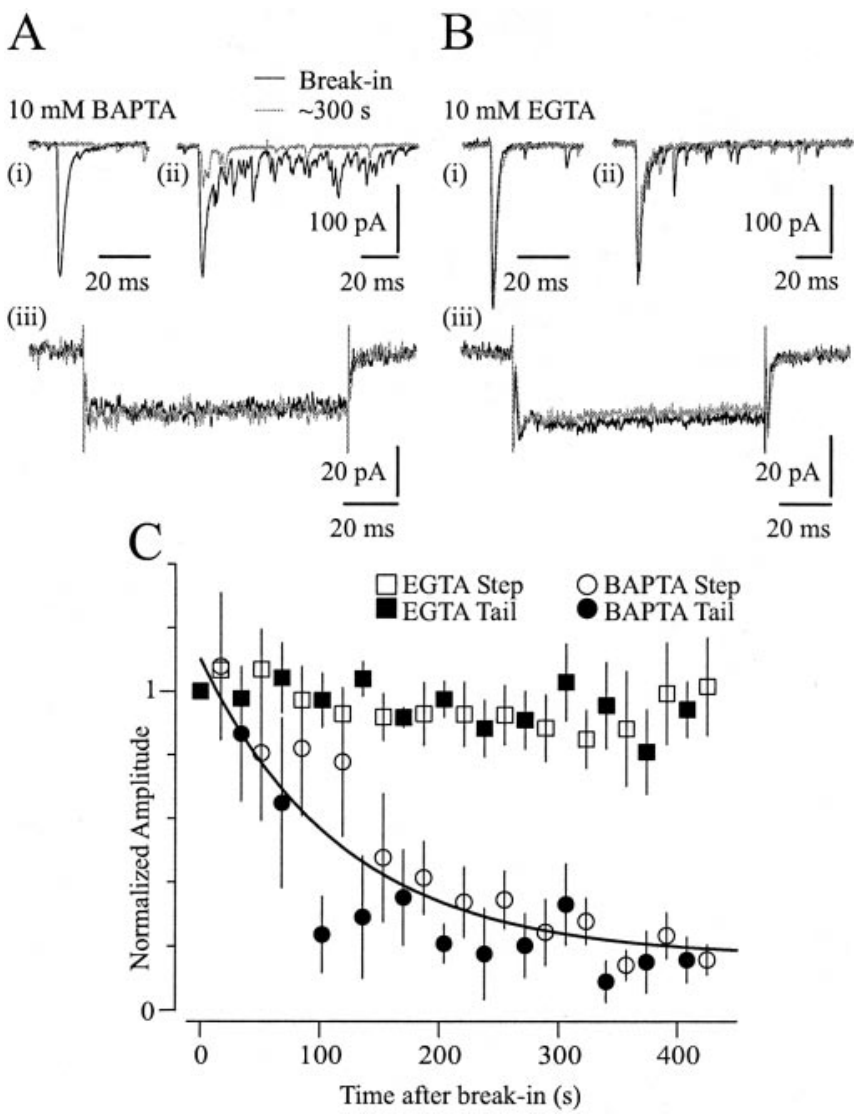

Figure 8. Transmission from RBC terminals is blocked rapidly by $10 \mathrm{~mm}$ BAPTA but not by 10 mм EGTA. A, Recordings with $10 \mathrm{~mm}$ BAPTA; responses were elicited by alternating tail currents and voltage steps from -60 to $-10 \mathrm{mV}$ in the RBC at 17 sec intervals. i, The first tEPSC (black), evoked within 15 sec of establishing a whole-cell presynaptic recording (time $=0$ ), is compared with one evoked $323 \mathrm{sec}$ later (gray). ii, Step-evoked EPSCs at time $=17 \mathrm{sec}$ (black) or $340 \mathrm{sec}$ (gray). iii, Presynaptic currents (averages of 3 sequential responses) from $t=17-85$ sec (black) or 272-340 sec (gray) show that $10 \mathrm{~mm}$ BAPTA does not affect $\mathrm{Ca}^{2+}$ influx into the presynaptic terminal. $B$, Recordings with $10 \mathrm{~mm}$ EGTA: $i$, ii, iii as in $A$. C, Summary of the effects of $10 \mathrm{~mm}$ BAPTA $(n=5)$ or $10 \mathrm{~mm}$ EGTA $(n=5)$ on EPSC amplitude. The peak amplitudes of individual responses from each cell were normalized to the peak amplitude of the first tEPSC recorded in that cell. The line is an exponential fit to the pooled (step- and tail-evoked) BAPTA data points; $\tau=125 \mathrm{sec}$.

kinetics and voltage dependence of $\mathrm{Ca}^{2+}$ currents were the same whether recorded at the soma or the axon terminals of RBCs in rat retinal slices, indicating that the axon does not preclude voltage control of the terminal from the soma. The waveform and current-voltage relationship of currents recorded here are consistent with those reported in that study. Second, stepping RBCs to $+90 \mathrm{mV}$ (near $E_{\mathrm{Ca} 2+}$ ) did not elicit EPSCs (Fig. 5), indicating that the clamp speed was faster than $\mathrm{Ca}^{2+}$ channel activation $(\leq 1$ $\mathrm{msec}$ ). Third, the EPSC was unaffected by inhibitory feedback, demonstrating that the somatic voltage clamp prevented chloride conductances from altering significantly the membrane potential at the terminal.

\section{Comparison with other ribbon synapses: exocytosis}

As with goldfish $\mathrm{Mb1}$ and mammalian inner hair cell ribbon synapses (Mennerick and Matthews, 1996; von Gersdorff et al., 1996, 1998; Moser and Beutner, 2000), exocytosis from RBCs can be rapid when not limited by $\mathrm{Ca}^{2+}$ channel activation (Figs. $4 B$, $5 A$ ). Rates of exocytosis from $\mathrm{Mb} 1$ and hair cell terminals are strongly $\mathrm{Ca}^{2+}$ dependent (Heidelberger et al., 1994; Beutner et al., 2001), consistent with our results showing that the EPSC waveform varies with presynaptic $\mathrm{Ca}^{2+}$ influx (Fig. 4).

Despite sustained presynaptic $\mathrm{Ca}^{2+}$ entry, EPSCs evoked in AIIs and A17s by depolarizing RBCs to -10 or $0 \mathrm{mV}$ were dominated by a transient component that likely reflects the intrinsic dynamics of release, because it persisted in the absence of inhibition and postsynaptic receptor desensitization (Fig. $1 B, C$ ). At other ribbon synapses, release rates decline over tens to hundreds of milliseconds, and this slowing of exocytosis may result from depletion of readily releasable vesicles (Mennerick and Matthews, 1996; von Gersdorff and Matthews, 1997; Moser and Beutner, 2000) (but see Burrone and Lagnado, 2000). The fast decay of the EPSCs here also could arise from vesicle depletion; the sustained component may reflect an equilibrium between release from and replenishment of a depleted vesicle pool.

Dual-component EPSCs were evoked with a range of exogenous, presynaptic $\mathrm{Ca}^{2+}$ buffer concentrations (Fig. 6), suggesting that both components reflect exocytosis from sites close to $\mathrm{Ca}^{2+}$ channels (Neher, 1998). In goldfish Mb1 terminals, a slower phase of exocytosis $\left(\tau_{\text {activation }} \sim 350 \mathrm{msec}\right)$, drawing from a distinct vesicle pool recruited as the readily releasable pool became depleted, was inhibited preferentially by 5 mM EGTA (Mennerick and Matthews, 1996). The slow phase of exocytosis from Mb1 terminals is not asynchronous release, because it terminates soon after presynaptic $\mathrm{Ca}^{2+}$ channels close (von Gersdorff et al., 1998). In $<5 \%$ of recordings, we observed a slowly developing component of the EPSC that appeared after $\sim 75 \mathrm{msec}$ of $\mathrm{Ca}^{2+}$ influx and clearly was distinct from the sustained component (data not shown). Because this phenomenon was observed so infrequently, we did not study it further. Von Gersdorff at al. (1998) concluded that when the $\mathrm{Ca}^{2+}$ current density was high the two components fused and were indistinguishable; it may be that the $\mathrm{Ca}^{2+}$ current density on rat RBC terminals is sufficiently high such that the EPSCs that we recorded reflect this sort of merged exocytosis. It also is possible that the 100 millisecond stimuli used here were not long enough to recruit a slow, second pool, although we did not observe any slowly developing components of the EPSCs evoked by $625 \mathrm{msec}$ steps (perforated-patch recordings; $n=8$; data not shown).

Asynchronous release results from elevated terminal steadystate $\left[\mathrm{Ca}^{2+}\right]$ (Barrett and Stevens, 1972), set by the buffer capacity of the terminal and its $\mathrm{Ca}^{2+}$ clearance mechanisms; in $\mathrm{Mb} 1$ neurons, clearance is accomplished by a plasma membrane $\mathrm{Ca}^{2+}$-ATPase (Zenisek and Matthews, 2000). Asynchronous release from rat $\mathrm{RBCs}$ required sustained $\mathrm{Ca}^{2+}$ entry into the presynaptic terminal (Fig. 7) and was enhanced when $\mathrm{Ca}^{2+}$ buffering was weak (0.2 mM EGTA) (Fig. 6A), consistent with capacitance measurements from RBC terminals (Pan et al., 2001). Accordingly, asynchronous release from Mb1 terminals requires a high, presynaptic $\mathrm{Ca}^{2+}$ current density (von Gersdorff et al., 1998).

\section{Comparison with other ribbon synapses: $\mathrm{Ca}^{2+}$ channels}

$\mathrm{RBC} \mathrm{Ca}{ }^{2+}$ currents evoked by steps from $-60 \mathrm{mV}$ were mostly sustained, suggesting that they are mediated by L-type channels, as in Mb1 and hair cell terminals (Tachibana et al., 1993; Moser and Beutner, 2000). Because such channels are confined to the terminals of mammalian RBCs (Protti and Llano, 1998; Satoh et al., 1998; Hartveit, 1999; Pan, 2001), we conclude that these currents reflect the $\mathrm{Ca}^{2+}$ entry that elicits release.

Low voltage-activated (T-type) $\mathrm{Ca}^{2+}$ currents have been recorded in rat RBCs (Hartveit, 1999; Pan, 2001; Pan et al., 2001). Activation of these currents must be preceded by membrane hy- 
perpolarization to permit recovery from inactivation (Klockner et al., 1999; Pan, 2000; Perez-Reyes, 2003); in RBCs, transient $\mathrm{Ca}^{2+}$ currents are not elicited by depolarization from $-60 \mathrm{mV}$ (Hartveit, 1999). Consistent with previous work (Pan et al., 2001), when RBCs were depolarized from $-100 \mathrm{mV}, \mathrm{Ca}^{2+}$ influx through T-type channels contributed to exocytosis (Fig. 3E). Mixed L- and T-type $\mathrm{Ca}^{2+}$ currents, however, activated more slowly than sustained currents (Fig. $3 E, F$ ) and evoked EPSCs that rose more gradually than those evoked by $\mathrm{Ca}^{2+}$ entry through L-type channels alone (Fig. 3E). The transient component of the EPSC, then, does not require T-channel activation.

\section{Feedback inhibition}

It has been proposed that reciprocal inhibitory synapses at RBC terminals make transmission from RBCs transient (Raviola and Dacheux, 1987), and several studies have demonstrated that feedback inhibition follows glutamate release from the RBC terminal (Protti and Llano, 1998; Hartveit, 1999; Pan et al., 2001). Exocytosis from RBC terminals, however, declines rapidly even in the absence of inhibition (Fig. $1 B$ ). In the absence of presynaptic voltage clamp, feedback inhibition may make EPSCs even more transient.

In contrast to Hartveit (1999), who reported that both $\mathrm{GABA}_{\mathrm{A}}$ and $\mathrm{GABA}_{C}$ Rs mediated feedback evoked by depolarizing single RBCs, we found that such inhibition normally was mediated by $\mathrm{GABA}_{\mathrm{A}}$ Rs only. We examined feedback coinciding with presynaptic $\mathrm{Ca}^{2+}$ entry ( $\mathrm{RBC} E_{\mathrm{Cl}}{ }^{-}=-50 \mathrm{mV} ; 1.5 \mathrm{~mm}$ BAPTA), however, and Hartveit (1999) studied feedback occurring after $\mathrm{Ca}^{2+}$ channel deactivation $\left(E_{\mathrm{Cl}}{ }^{-}=0 \mathrm{mV} ; 0.1 \mathrm{~mm}\right.$ EGTA). With low [EGTA], vigorous asynchronous release (Fig. $6 A$ ) likely triggered feedback mediated by both $\mathrm{GABA}_{\mathrm{A}}$ and $\mathrm{GABA}_{\mathrm{C}}$ Rs.

Increased postsynaptic excitation resulting from asynchronous release might have enhanced GABA release from amacrine cells sufficiently to activate $\mathrm{GABA}_{\mathrm{C}} \mathrm{Rs}$. This possibility is supported by the effects of CTZ observed here. The outward current that appeared in RBCs in the presence of CTZ was blocked by TPMPA, indicating that it reflects GABAergic feedback onto GABA $_{C}$ Rs (Fig. 1C). Moreover, EPSCs in A17s (which provide the GABAergic input to the RBC terminal) were potentiated by CTZ (Fig. 2C). Hartveit (1996) also evoked GABA ${ }_{C}$ R-mediated currents in RBCs by applying kainate in the IPL. It seems likely, then, that enhancing GABA release from postsynaptic amacrine cells by increasing their excitability with CTZ (Fig. 2C), kainate (Hartveit, 1996), or asynchronous release from RBCs (Hartveit, 1999) leads to the activation of $G_{A B A}$ Rs. Because $G_{A B A}$ and $\mathrm{GABA}_{\mathrm{C}} \mathrm{Rs}$ are not colocalized on RBC terminals (Koulen et al., 1997, 1998; Fletcher et al., 1998), it is possible that the $\mathrm{GABA}_{\mathrm{C}} \mathrm{Rs}$ on RBCs are targeted to synapses that have a low release probability or encounter relatively low [GABA] [see also Matsui et al. (2001) and Ichinose and Lukasiewicz (2002)].

\section{Implications for synaptic transmission in the mammalian rod circuit}

Several components of the rod circuit may interact with RBC input to sculpt light responses in AII and A17 amacrine cells: feedback inhibition onto RBC terminals, lateral inhibition between amacrine cells, gap junctions between component neurons, the convergence of many RBCs onto a single postsynaptic target, and active conductances within these neurons. To appreciate how these factors contribute to signal processing during a light response, however, it is essential to understand the intrinsic characteristics of RBC synapses.

Although light-evoked responses in RBCs are slow and sus- tained (Berntson and Taylor, 2000; Euler and Masland, 2000), the intrinsic release properties and fast postsynaptic receptor kinetics permit phasic transmission at RBC synapses. The sustained light responses of A17s (Kolb and Nelson, 1983; Nelson and Kolb, 1985; Raviola and Dacheux, 1987; Menger and Wassle, 2000), then, may reflect the integration of many small, spatially scattered synaptic inputs that are filtered electrotonically by the extensive dendritic arbor of the cell. Were this true, the characteristics of reciprocal feedback inhibition from A17s to RBCs would follow more closely the time course of vesicle release from the RBC (Fig. $1 B$ ) than the ensemble light-evoked response recorded at the A17 soma.

AII light responses exhibit both transient and sustained components (Nelson, 1982; Kolb and Nelson, 1983; Dacheux and Raviola, 1986; Bloomfield and Xin, 2000). The transient component becomes more prominent with increasing light intensity (Nelson, 1982), which is caused, perhaps, by the increased transience of EPSCs after larger presynaptic depolarizations (Fig. $4 B$ ). Thus, the initial, transient component of vesicle release from the $\mathrm{RBC}$ terminal may serve to signal the rate of change in light intensity. The later, more sustained component of transmission may encode the duration of the light stimulus and also may be altered by electrotonic coupling within the AII network. It appears, however, that the RBC-AII synapse is well equipped to "quicken" signaling in the rod pathway, as suggested by Nelson (1982).

\section{References}

Barrett EF, Stevens CF (1972) The kinetics of transmitter release at the frog neuromuscular junction. J Physiol (Lond) 227:691-708.

Berntson A, Taylor WR (2000) Response characteristics and receptive field widths of on-bipolar cells in the mouse retina. J Physiol (Lond) 524:879-889.

Beutner D, Voets T, Neher E, Moser T (2001) Calcium dependence of exocytosis and endocytosis at the cochlear inner hair cell afferent synapse. Neuron 29:681-690.

Bloomfield SA, Dacheux RF (2001) Rod vision: pathways and processing in the mammalian retina. Prog Retin Eye Res 20:351-384.

Bloomfield SA, Xin D (2000) Surround inhibition of mammalian AII amacrine cells is generated in the proximal retina. J Physiol (Lond) 523:771-783.

Bowie D, Mayer ML (1995) Inward rectification of both AMPA and kainate subtype glutamate receptors generated by polyamine-mediated ion channel block. Neuron 15:453-462.

Burrone J, Lagnado L (2000) Synaptic depression and the kinetics of exocytosis in retinal bipolar cells. J Neurosci 20:568-578.

Burrone J, Neves G, Gomis A, Cooke A, Lagnado L (2002) Endogenous calcium buffers regulate fast exocytosis in the synaptic terminal of retinal bipolar cells. Neuron 33:101-112.

Clements JD, Lester RA, Tong G, Jahr CE, Westbrook GL (1992) The time course of glutamate in the synaptic cleft. Science 258:1498-1501.

Dacheux RF, Raviola E (1986) The rod pathway in the rabbit retina: a depolarizing bipolar and amacrine cell. J Neurosci 6:331-345.

Diamond JS, Jahr CE (1997) Transporters buffer synaptically released glutamate on a submillisecond time scale. J Neurosci 17:4672-4687.

Euler T, Masland RH (2000) Light-evoked responses of bipolar cells in a mammalian retina. J Neurophysiol 83:1817-1829.

Euler T, Wassle H (1995) Immunocytochemical identification of cone bipolar cells in the rat retina. J Comp Neurol 361:461-478.

Famiglietti EV, Kolb H (1975) A bistratified amacrine cell and synaptic circuitry in the inner plexiform layer of the retina. Brain Res 84:293-300.

Feigenspan A, Wassle H, Bormann J (1993) Pharmacology of GABA receptor $\mathrm{Cl}^{-}$channels in rat retinal bipolar cells. Nature 361:159-162.

Fletcher EL, Koulen P, Wassle H (1998) GABAA and GABAC receptors on mammalian rod bipolar cells. J Comp Neurol 396:351-365.

Fletcher EL, Hack I, Brandstatter JH, Wassle H (2000) Synaptic localization of NMDA receptor subunits in the rat retina. J Comp Neurol 420:98-112.

Ghosh KK, Haverkamp S, Wassle H (2001) Glutamate receptors in the rod pathway of the mammalian retina. J Neurosci 21:8636-8647. 
Hartveit E (1996) Membrane currents evoked by ionotropic glutamate receptor agonists in rod bipolar cells in the rat retinal slice preparation. J Neurophysiol 76:401-422.

Hartveit E (1997) Functional organization of cone bipolar cells in the rat retina. J Neurophysiol 77:1716-1730.

Hartveit E (1999) Reciprocal synaptic interactions between rod bipolar cells and amacrine cells in the rat retina. J Neurophysiol 81:2923-2936.

Hartveit E, Veruki ML (1997) AII amacrine cells express functional NMDA receptors. NeuroReport 8:1219-1223.

Heidelberger R, Heinemann C, Neher E, Matthews G (1994) Calcium dependence of the rate of exocytosis in a synaptic terminal. Nature 371:513515.

Ichinose T, Lukasiewicz PD (2002) GABA transporters regulate inhibition in the retina by limiting $\operatorname{GABA}(\mathrm{C})$ receptor activation. J Neurosci 22: 3285-3292.

Jonas P, Racca C, Sakmann B, Seeburg PH, Monyer H (1994) Differences in $\mathrm{Ca}^{2+}$ permeability of AMPA-type glutamate receptor channels in neocortical neurons caused by differential GluR-B subunit expression. Neuron 12:1281-1289.

Klockner U, Lee JH, Cribbs LL, Daud A, Hescheler J, Pereverzev A, PerezReyes E, Schneider T (1999) Comparison of the $\mathrm{Ca}^{2+}$ currents induced by expression of three cloned alphal subunits, alpha1G, alpha1H and alpha1I, of low-voltage-activated T-type $\mathrm{Ca}^{2+}$ channels. Eur J Neurosci 11:4171-4178.

Kolb H, Nelson R (1983) Rod pathways in the retina of the cat. Vision Res 23:301-312.

Koulen P, Brandstatter JH, Kroger S, Enz R, Bormann J, Wassle H (1997) Immunocytochemical localization of the $\mathrm{GABA}(\mathrm{C})$ receptor rho subunits in the cat, goldfish, and chicken retina. J Comp Neurol 380:520-532.

Koulen P, Brandstatter JH, Enz R, Bormann J, Wassle H (1998) Synaptic clustering of $\mathrm{GABA}(\mathrm{C})$ receptor rho-subunits in the rat retina. Eur J Neurosci 10:115-127.

Li W, Trexler EB, Massey SC (2002) Glutamate receptors at rod bipolar ribbon synapses in the rabbit retina. J Comp Neurol 448:230-248.

Matsui K, Hasegawa J, Tachibana M (2001) Modulation of excitatory synaptic transmission by $\mathrm{GABA}(\mathrm{C})$ receptor-mediated feedback in the mouse inner retina. J Neurophysiol 86:2285-2298.

Menger N, Wassle H (2000) Morphological and physiological properties of the A17 amacrine cell of the rat retina. Vis Neurosci 17:769-780.

Mennerick S, Matthews G (1996) Ultrafast exocytosis elicited by calcium current in synaptic terminals of retinal bipolar neurons. Neuron 17:1241-1249.

Morkve SH, Veruki ML, Hartveit E (2002) Functional characteristics of non-NMDA-type ionotropic glutamate receptor channels in AII amacrine cells in rat retina. J Physiol (Lond) 542:147-165.

Moser T, Beutner D (2000) Kinetics of exocytosis and endocytosis at the cochlear inner hair cell afferent synapse of the mouse. Proc Natl Acad Sci USA 97:883-888.

Neher E (1998) Vesicle pools and $\mathrm{Ca}^{2+}$ microdomains: new tools for understanding their roles in neurotransmitter release. Neuron 20:389-399.

Nelson R (1982) AII amacrine cells quicken time course of rod signals in the cat retina. J Neurophysiol 47:928-947.

Nelson R, Kolb H (1985) A17: a broad-field amacrine cell in the rod system of the cat retina. J Neurophysiol 54:592-614.

Okada T, Horiguchi H, Tachibana M (1995) $\mathrm{Ca}(2+)$-dependent $\mathrm{Cl}^{-}$cur- rent at the presynaptic terminals of goldfish retinal bipolar cells. Neurosci Res 23:297-303.

Pan ZH (2000) Differential expression of high- and two types of lowvoltage-activated calcium currents in rod and cone bipolar cells of the rat retina. J Neurophysiol 83:513-527.

Pan $\mathrm{ZH}$ (2001) Voltage-activated $\mathrm{Ca}^{2+}$ channels and ionotropic GABA receptors localized at axon terminals of mammalian retinal bipolar cells. Vis Neurosci 18:279-288.

Pan ZH, Lipton SA (1995) Multiple GABA receptor subtypes mediate inhibition of calcium influx at rat retinal bipolar cell terminals. J Neurosci 15:2668-2679.

Pan ZH, Hu HJ, Perring P, Andrade R (2001) T-type Ca(2+) channels mediate neurotransmitter release in retinal bipolar cells. Neuron 32:89-98.

Partin KM, Patneau DK, Winters CA, Mayer ML, Buonanno A (1993) Selective modulation of desensitization at AMPA versus kainate receptors by cyclothiazide and concanavalin A. Neuron 11:1069-1082.

Perez-Reyes E (2003) Molecular physiology of low-voltage-activated t-type calcium channels. Physiol Rev 83:117-161.

Pourcho RG, Goebel DJ (1985) A combined Golgi and autoradiographic study of $(3 \mathrm{H})$ glycine-accumulating amacrine cells in the cat retina. J Comp Neurol 233:473-480.

Protti DA, Llano I (1998) Calcium currents and calcium signaling in rod bipolar cells of rat retinal slices. J Neurosci 18:3715-3724.

Raviola E, Dacheux RF (1987) Excitatory dyad synapse in rabbit retina. Proc Natl Acad Sci USA 84:7324-7328.

Rosenberg RL, Hess P, Tsien RW (1988) Cardiac calcium channels in planar lipid bilayers. L-type channels and calcium-permeable channels open at negative membrane potentials. J Gen Physiol 92:27-54.

Satoh H, Aoki K, Watanabe SI, Kaneko A (1998) L-type calcium channels in the axon terminal of mouse bipolar cells. NeuroReport 9:2161-2165.

Slaughter MM, Miller RF (1981) 2-Amino-4-phosphonobutyric acid: a new pharmacological tool for retina research. Science 211:182-185.

Tachibana M, Okada T, Arimura T, Kobayashi K, Piccolino M (1993) Dihydropyridine-sensitive calcium current mediates neurotransmitter release from bipolar cells of the goldfish retina. J Neurosci 13:2898-2909.

Veruki ML, Hartveit E (2002) AII (Rod) amacrine cells form a network of electrically coupled interneurons in the mammalian retina. Neuron 14: 935-946.

Veruki ML, Morkve SH, Hartveit E (2003) Functional properties of spontaneous EPSCs and non-NMDA receptors in rod amacrine (AII) cells in the rat retina. J Physiol (Lond) 549:759-774.

von Gersdorff H, Matthews G (1997) Depletion and replenishment of vesicle pools at a ribbon-type synaptic terminal. J Neurosci 17:1919-1927.

von Gersdorff H, Vardi E, Matthews G, Sterling P (1996) Evidence that vesicles on the synaptic ribbon of retinal bipolar neurons can be rapidly released. Neuron 16:1221-1227.

von Gersdorff H, Sakaba T, Berglund K, Tachibana M (1998) Submillisecond kinetics of glutamate release from a sensory synapse. Neuron 21:1177-1188.

Zenisek D, Matthews G (2000) The role of mitochondria in presynaptic calcium handling at a ribbon synapse. Neuron 25:229-237.

Zhang J, Li W, Trexler EB, Massey SC (2002) Confocal analysis of reciprocal feedback at rod bipolar terminals in the rabbit retina. J Neurosci 22: 10871-10882. 